\title{
The Role of Work Engagement in Agile Software Development: Investigating Job Demands and Job Resources
}

\author{
Veronika Huck-Fries \\ Technical University of Munich \\ veronika.fries@in.tum.de
}

\author{
Barbara Prommegger \\ Technical University of Munich \\ barbara.prommegger@in.tum.de \\ Helmut Krcmar \\ Technical University of Munich \\ krcmar@in.tum.de
}

\author{
Manuel Wiesche \\ Technical University of Munich \\ wiesche@in.tum.de
}

\begin{abstract}
Agile software development projects still show a high failure rate. Despite a growing amount of research, underlying reasons for project performance currently remain rare. Drawing on the job demandsresources theory, we propose a theoretical model of work engagement in agile software development teams. Using structural equation modeling, we found that agile practices diminish job demands (perceived workload and role ambiguity) and support job resources (perceived meaningfulness and job autonomy). Job resources have been found to be positively related to work engagement in agile software development teams. Our research contributes to the limited empirical understanding on work engagement in agile software development. For practitioners, our model provides tools to effectively manage team members' work engagement.
\end{abstract}

\section{Introduction}

The main purpose of this research is to identify the relationship between agile software development (ASD) practices and work engagement in ASD teams. We advance the view that ASD per se leads to project success and point out the not well studied role of both job demands and job resources in ASD. The contribution of this paper is to identify the particular job demands and resources, job aspects, which require effort and job aspects, that help to achieve goals, of team members in ASD and quantify their effect on team members' work engagement.

Over the last decades, ASD practices have been applied by a growing amount of companies [57]. In 2017, 9 out of 10 software companies stated that they work according to agile principles [18]. ASD practices have been developed in order to provide the possibility to quickly react to varying customer demands and facilitate project planning, even if the target of a project cannot be exactly defined right from the beginning [59]. Instead of striving for the perfect, complete product right from the start, ASD prioritizes the customer's needs and gradually processes them in order to learn from feedback and drawbacks. Since studies have shown that failing in IT projects can lead to a positive learning success, this approach promises beneficial long-term effects [35].

According to the Agile Manifesto [19], ASD claims to increase motivation and well-being of team members as individuals and interaction are valued over processes and tools. The principles state that motivated individuals who are provided with the required environment and support and are trusted to get the work done and demonstrate better performance. The human factors are therefore crucial for the success or failure of ASD projects [1].

However, ASD practices and their application cannot guarantee success of development projects. In 2015, about one third of ASD projects had been completed successfully, leaving $61 \%$ of challenging or even failed projects [51]. Even though agile methods are extremely popular, their effectiveness remains unclear and is largely based on anecdotal or small sample size research [e.g. 49].

With the increasing need for complex social interaction between involved team members, new job demands and resources arise in ASD teams. On the one hand, iterative delivery cuts work packages into manageable sized pieces and provides a better workload balance [29]. Above, by introducing flat hierarchies, ASD generates a clear picture of responsibility between the involved persons [25] and might decrease individuals' role ambiguity. On the 
other hand, the ability to deliver complete parts, such as a User Story, increases identification with work [56] and is hypothesized to determine perceived meaningfulness. In addition, self-organization is a decisive principle of agile practices [25], which is argued to foster job autonomy in ASD teams.

In a highly competitive business such as software development, organizations rely on individual engagement of employees. Work engagement, a workrelated state of mind, characterized by feeling energetic and immersed, has been found to be a predictor of both job and organizational performance as well as key organizational outcomes, such as innovation, creativity and reduced absenteeism due to sickness [7]. Above, work engagement acts as one of the key indicators for well-being at work and is related to job satisfaction and turnover intention of information systems (IS) professionals [26, 48, 56]. In ASD teams, wellbeing has been found to be directly related to project performance [38]. It is an important performancerelated indicator and acts as a mediator between employee attitudes and outcomes [7].

Our research into job demands and resources in ASD evolved from the perspective: What are the effects of the use of agile practices on job demands, job resources and work engagement in ASD teams?

To answer this research question, we developed and validated a research model that investigates agile practices, job demands and job resources and their effect on team members' work engagement. Our results contribute to the literature by illustrating that agile practices diminish job demands (perceived workload and role ambiguity) and foster job resources (perceived meaningfulness and job autonomy). We show that job resources positively affect work engagement in ASD teams.

The paper is structured as follows: section 2 presents the theoretical foundation around ASD and work engagement. In Section 3, we explain our research model and hypothesis in detail. Section 4 presents the methodological procedure. In section 5, we illustrate our results and section 6 contains the discussion and our conclusion.

\section{Theoretical background}

\subsection{Agile software development}

In our paper, we draw on [14], which defines ASD as "the continual readiness of an information systems development method to rapidly or inherently create change, proactively or reactively embrace change, and learn from change while contributing to perceived customer value (economy, quality, and simplicity), through its collective components and relationships with its environment".

Human factors have been found to be crucial for success or failure of ASD projects [1]. In accordance with existing literature on the impact of developers' personality in IT projects [58], Misra, Kumar [34] found a significant relationship between personal characteristics and success of ASD projects. Agility furthermore has a positive influence on team structures [36]. Since every new project includes its own goals and requirements, agile development has "a powerful social aspect, stimulating human interaction at the workplace and team spirit" [52]. Emerging working conditions are crucial in terms of employees' work engagement including factors like intrinsic motivation, job satisfaction and turnover intention, which can heavily influence a future organizational success [15].

\subsection{Job demands resources-theory}

The job demands-resources theory (JD-R theory) states that working environments can be divided into two broad categories: job demands and job resources [8]. Job demands refer to aspects of a job that require psychological and/or physical effort and is thus associated with a certain amount of costs. Job resources includes aspects of a job that are beneficial in achieving goals, are able to reduce job demands and related costs or encourage learning, development and personal growth.

Both demands and resources have been found to be directly or indirectly associated with work engagement of employees. [46] defined work engagement as "the positive, fulfilling and work-related state of mind that is characterized by vigor, dedication, and absorption". Vigor is associated with a high level of mental resilience and energy during work-related activities. Highly engaged employees invest noticeable efforts in their work and persist when facing challenges and difficulties. Dedication is associated with a high amount of involvement in work and a perception of joy and significance. Absorption refers to a state of being fully immersed and concentrated at work. Highly engaged employees often report that they forget time and environment while working. Work engagement is related to better health, more positive emotions and thus increased well-being of employees [46] as well as job performance.

\section{Research Model}

In this section, we develop our research model. As shown above, previous literature indicates that agile practices have been investigated in the relationship of 
job satisfaction [56], motivation [33] or stress [29]. Our model investigates the effect of ASD practices on team members' job demands, job resources and their work engagement. In regard to job demands, we argue that agile practices have an influence on perceived workload and role ambiguity. In regard to job resources, we assume that perceived meaningfulness and job autonomy are affected. We subsequently theorize about the impact that job demands and job resources have on work engagement.

\subsection{Agile practices and job demands}

Based on our literature review, we hypothesize that agile practices are negatively related to job demands.

Perceived workload is defined as "the perceived amount of work to be accomplished in the allotted time." [6]. IS professionals suffer from large workloads and from deadline pressure. Due to long working hours or even night shifts, work overload has a strong impact on the feeling of work exhaustion of professionals in the IS domain [4]. Oncall-duty and the necessity to be accessible around the clock contribute to an increased feeling of pressure and perceived workload [6]. In addition, exposure to interruptions by technology (e.g. email) has been found to increase individuals' perceived workload [2].

Iterative delivery cuts work packages into manageable sized pieces and provides a better workload balance [29]. Working in iterations improves speed and flexibility on the one hand, but also requires a quicker response to problems and issues on the other hand. To reduce the risk of causing stress among team members [5], it is especially important to strive for sustainable pace and workload [29]. Agile methodology deals with these new challenges by focusing on self-organized teams [54]. Based on these reasons, we hypothesize that The extent of use of agile practices negatively impacts team members' perceived workload (Hla).

Role ambiguity describes the uncertainty regarding role expectations, as well as work targets [17]. Uncertainty about roles and their responsibilities creates uncertainty about the performance of the work. This, in turn, leads to stress and affects job satisfaction and work adjustment negatively [27]. Role ambiguity has been reported as one main source of stress in IS as it has a negative impact on job satisfaction and relates to the intention of turnover [21]. Furthermore, [60] found a negative relationship between role ambiguity and productivity among IS professionals. [44] assume that IS professionals with a preference for logic are particularly susceptible to uncertainties regarding role understanding.

Agile practices try to pool resources within teams and consequently define and distribute roles unambiguously. By introducing flat hierarchies, ASD generates a clear picture of responsibility among the involved persons [25]. Breaking down work to the level of User Stories or even Tasks leads to a clear transparency of requirements and responsibility [42]. We therefore propose The extent of use of agile

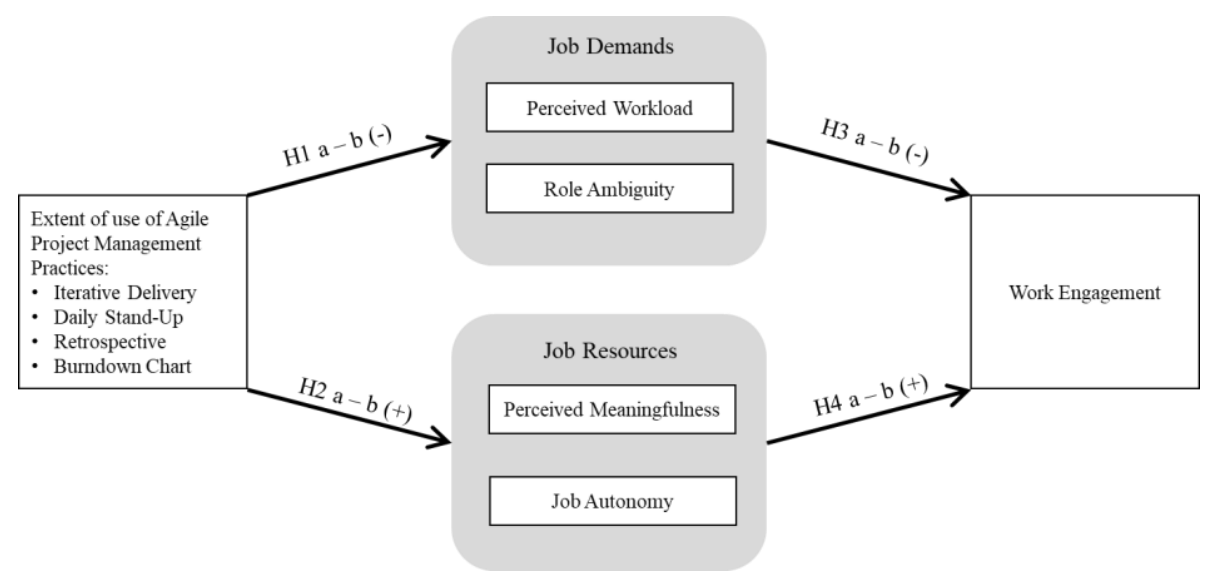

Figure 1: Research model

practices negatively impacts team members' role ambiguity (H1b).

\subsection{Agile practices and job resources}

We hypothesize that agile practices are positively related to job resources. Figure 1 illustrates our research model.

Perceived meaningfulness is defined as the perception of an employee concerning the amount of significance of his/her job [43]. It describes the conviction of employees how much their job impacts the lives of others, whether within an organization or within society in general [22].

Because software engineers tend to underestimate the value of their own work [16], regular user contact is valuable in order to gain objective feedback and recognize the impact of work. By regular user feedback, the team member recognition of the importance of the implemented work and its effective application. In combination with the ability to deliver not only specific parts, such as the design of the code, 
but rather a complete User Story, identification with the work increases [56]. We therefore suggest that The extent of use of agile practices positively impacts team members' perceived meaningfulness $(\mathrm{H} 2 \mathrm{a})$.

Job autonomy is "the degree to which the job provides substantial freedom, independence and discretion in scheduling the work and in determining the procedures to be used in carrying it out" [22]. IS professions experience high autonomy since the domain affords more opportunities to design job characteristics and tasks [3]. Autonomy has increased in the last years in the IS sector [21]. It decentralizes decision-making to those who actually carry out the work [53]. Empowered teams show higher level of response efficiency, which means that they are more efficient in responding to changing of requirements [30]. Furthermore, job autonomy reduces perceived workload, work exhaustion and the intention to leave the job [4, 21].

Self-organization on the level of the team, but also on the individual level, is a decisive principle of agile practices [25]. This principle is for example followed by team based estimation or team based decisions about workload for the next sprint [54]. We therefore suggest that The extent of use of agile practices positively impacts team members' job autonomy $(\mathrm{H} 2 \mathrm{~b})$.

\subsection{Job demands, job resources and work engagement}

The JD-R model demonstrates that work engagement is a function of job demands and resources in the organization [7]. There is ample evidence that job demands are negatively related to employees' work engagement, while job resources positively affect employees' engagement (for a review, see [9]). Therefore, we hypothesize that Perceived workload and role ambiguity negatively impact team members' work engagement (H3a-b) and Perceived meaningfulness and job autonomy positively impact team members' work engagement ( $\mathrm{H} 4 \mathrm{a}-\mathrm{b})$.

\section{Research Method}

\subsection{Study design}

Our study was conducted in cooperation with company "agile", a German company operating in the automotive industry. This company has used ASD practices since 2016 companywide. For the purpose of investigating the effect of agile practices on demands, resources and work engagement, we chose structural equation modeling. An appropriate analysis technique for our model is partial least squares structural equation modeling (PLS-SEM) as the theory of our study has not been established yet and ASD practices are modeled as a second-order construct [37] We selected SmartPLS as the appropriate software tool [40]. As a guideline, we followed the instructions from [23].

\subsection{Participants}

We defined members of teams who are using ASD practices as the target group for our survey. We intended to reach employees, engaged in software engineering, with various degree of agile experience, as well as different roles within the teams (Scrum Master, Product Owner, Business Analysts, Software Developer etc.). Based on these perimeters, we sent the survey to 380 persons from different departments, using agile methods. 172 survey responses were achieved, which represents a response rate of $45 \%$.

The respondents' demographics can be found in Table 1. Most of the respondents were Project Managers (including Scrum Masters and Product Owners,52 \% Senior Managers: $12 \%$ ). The remaining ones were Business Analysts (15\%), Software Developers $(9 \%)$ or Others (12\%). $60 \%$ of all respondents used agile practices for the last $1 \frac{1 / 2}{2}$ years or longer, $34 \%$ stated that they had begun to use agile principles in the last 6 months.

Table 1: Participants demographics

\begin{tabular}{|l|c|}
\hline \multicolumn{2}{|l|}{ Participants Demographics (n=130) } \\
\hline Function in company \\
\hline Project Manager & $52 \%$ \\
\hline Business / Systems Analyst & $15 \%$ \\
\hline Senior Manager & $12 \%$ \\
\hline Software Developer & $9 \%$ \\
\hline Others & $12 \%$ \\
\hline Agile work experience \\
\hline$<6$ months of agile work exp. & $34 \%$ \\
\hline 6 months - 1 1/2 years of agile work exp. & $41 \%$ \\
\hline $1 \frac{1}{2}$ year - 3 years agile work exp. & $7 \%$ \\
\hline$>3$ years of agile work exp. & $12 \%$ \\
\hline I don't use agile practices. & $6 \%$ \\
\hline
\end{tabular}

\subsection{Measures}

Only established measurement scales published in prior research with good quality criteria were chosen [39]. For the purpose of picking the most important agile practices, we conducted a pre-survey with 15 
selected representatives. We intended to cover a picture of the final sample as exact as possible and therefore chose representatives from different divisions, with various roles and different degree of agile experience. To measure the extent of these agile project management practices, we oriented on [56]. The results of the pre-survey showed that iterative delivery, daily stand-up, retrospective and burndown chart were the most applied agile practices in the company. $80 \%$ of all respondents used iterative delivery and stand-up, $70 \%$ used retrospective and 50 $\%$ used burndown chart.

Perceived workload was assessed using a four-item scale from [28]. Role ambiguity was measured with a scale developed by [41]. For assessing perceived meaningfulness and job autonomy, we used scales from the job diagnostic survey [22]. Finally, work engagement was measured with the short form of the Utrecht Work Engagement Scale [47]. For measuring demands and resources, we used a 7-point Likert scale, ranging from 1 (strongly disagree) to 7 (strongly agree). For assessing the extent of use of agile practices, we added "don't know" as an additional option. Work engagement was measured by a 7-point frequency rating scale from 1 (never) to 7 (always).

\section{Research Analysis and Results}

\subsection{Research Analysis}

We modelled the structural equation model based on our research model. We defined all dimensions as reflective, with one exception. We designed the "Agile Practices" construct as a reflective-formative secondorder construct [10], which is composed of the four practices iterative delivery, stand-up, retrospective and burndown chart.

A multilevel approach for assessing structural equation models was used. First, we modelled the effects of demands and resources on the dependent variable work engagement and called it "Model 1". Collectively, the manifest variables explained $58.4 \%$ of the variance of work engagement. As a next step, we included the agile practices constructs and called the resulting model "Model 2". This supplement had the effect of an increased variance of WE: $58.8 \%$. This small increase already suggested that no significant change was seen. The subsequent test supported this assumption. In order to test whether this increase was significant, we followed the instructions of [50] and [11] and calculated: $\mathrm{f}^{2}=\left(\mathrm{R}^{2} \mathrm{Model}_{2}-\mathrm{R}^{2} \mathrm{Model}_{1}\right) /(1-$ $\left.\mathrm{R}^{2} \mathrm{Model}_{2}\right)$. Furthermore we did a pseudo F-test $\left(f^{2 *}(\mathrm{n}\right.$ $\mathrm{k}-1)$ ), where $\mathrm{n}$ stands for sample size and $\mathrm{k}$ for the number of independent variables [32]. The results of the $\mathrm{f}^{2}(.010)$ and the F-Test indicated that the adding of agile practices did not result in significant change of work engagement (WE: $F=1.2$, df: 1, 130).

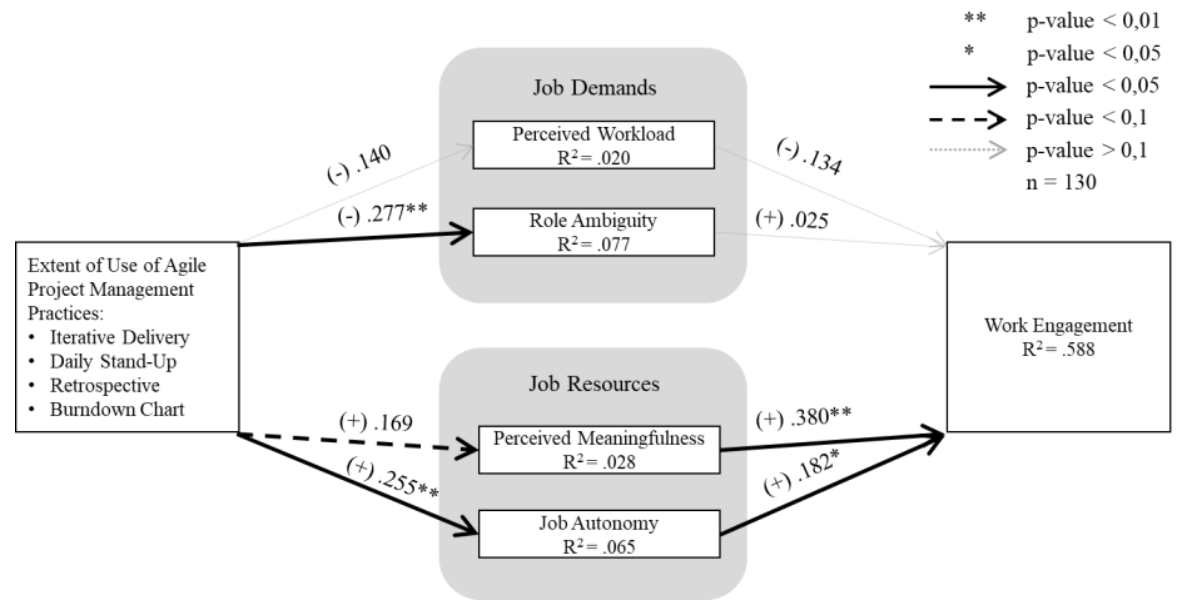

Figure 2: Path analysis results

In order to evaluate the measurement model, we conducted tests for internal consistency reliability, convergent validity and discriminant validity. All constructs had a Cronbach's alpha and a composite reliability that exceeded 0.7 [13]. The outer loadings, as well as the AVE indicated convergent validity. Furthermore, the cross loadings [20], the FornellLarcker criterion [23] and the Heterotrait-Monotrait Ratio [24] proved the constructs' discriminant validity. In order to assess the validity of our formative $2^{\text {nd }}$ order construct, we followed the guidelines of [23, 37]. The results of the validation showed that all $1^{\text {st }}$ order constructs loaded significantly on the second-order construct. Furthermore, all $1^{\text {st }}$ order constructs correlated, which is preferable, as we defined the $2^{\text {nd }}$ order construct as an aggregate construct [37]. Therefore, we conclude that the modelling of our $2^{\text {nd }}$ order construct is valid.

After ensuring the validity of the measurement model, we evaluated the structural model, by investigating collinearity, the f2, Q2 and the R2 values. All values of VIF were clearly beneath the critical value of 5 , which proves the correctness of the model [23]. The values for $\mathrm{f}^{2}$ had an acceptable, but rather small effect size. In order to evaluate predictive relevance, we checked for 
$\mathrm{Q}^{2}$ by using the blindfolding procedure [23]. All endogenous variables showed $\mathrm{Q}^{2}$ values over 0 , which suggested predictive relevance for the endogenous constructs. For evaluating the model's predictive accuracy, we investigated the $\mathrm{R}^{2}$ value for WE. WE showed values of 0.588 , which demonstrates a moderate effect.

\subsection{Results}

The results of the estimation process are visualized in Figure 2. We found evidence of the positive impact of agile practices on job demands. The effect of agile practices on perceived workload was not marginally significant $(.140, \mathrm{p}=0.100)$, which means that in our study, agile practices were not able to reduce the perceived workload of agile team members. Role ambiguity was significantly influenced by the extent of use of agile practices $(.277, \mathrm{p}<0.01)$. Thus, the results prove the positive influence of agility on job demands such as role ambiguity, and hypotheses $1 \mathrm{a}-\mathrm{b}$ can be partially supported.

Furthermore, the model demonstrates the significant influence on job resources. Developers' perceived meaningfulness $(.169, \mathrm{p}<0.1)$ and job autonomy $(.255, \mathrm{p}<0.01)$ increased significantly with the extent of use of agile practices. Agile practices therefore positively influences the working conditions of IT professionals by strengthening job resources. Thus, Hypotheses $2 \mathrm{a}-\mathrm{b}$ are

supported.

We found little evidence that job demands affect work engagement negatively. Team members' perceived workload $(.134, \mathrm{p}=0.206)$ weakens their work engagement, while role ambiguity $(.025, \mathrm{p}=$ 0.752 ) increases work engagement. Hypotheses $3 \mathrm{a}-\mathrm{b}$ can be partially supported. Job resources, on the other hand, positively predict team members' work engagement.

Perceived meaningfulness $(.380, \mathrm{p}<0.01)$ and job autonomy $(.182, \mathrm{p}<0.05)$ had a significantly positive effect on work engagement. This result indicates that resources had a much greater impact on engagement than demands did. Finally, Hypotheses 4 a-b can be supported.

\section{Discussion and Conclusion}

In general, the findings of the present study align well with previous research results $[6,29,33,56]$. As in previous studies, we reveal that both particular job demands and resources predicting work engagement of employees [6]. This provides further evidence on the previous conclusion that agile practices affect wellbeing of employees $[29,33,56]$.

We also provide additional insights that exceed the results of previous research. When focusing on the use of agile practices, prior IS research considered constructs of job satisfaction [56] and stress [29]. Furthermore, most of previous IS research did not assess the level of use of agile practice, "but rather just the high level concept of use of that method" [55].

The present study theorized and empirically validated the influence of the extent of use of agile practices on job demands, perceived workload and role ambiguity, and job resources, perceived meaningfulness and job autonomy in ASD teams. Moreover, the impact of job demands and resources on work engagement was assessed.

Three essential findings can be drawn from the results of our study. First, we could show that the extent of use of agile practices negatively impacts job demands in ASD (hypotheses 1a-b). The application of agile practices had a negative and significant effect on team members' role ambiguity. Second, the extent of use of agile practices positively impacts job resources in ASD (hypotheses 2a-b). Team members' perceived meaningfulness and their job autonomy increased with the extent of use of agile practices. Third, while job demands only have small impact on team members' work engagement in ASD, job resources significantly increase work engagement (hypotheses 3a-b, hypotheses 4a-b). These findings contain several theoretical and practical implications, which are discussed in the following.

\subsection{Theoretical implications}

As accentuated in the paper, this research focuses on ASD and the JD-R theory [8] by considering the different job demands and resources and their influence on work engagement in ASD projects. The theoretically developed and empirically evaluated model is the first step to differentiate between job demands and resources in ASD projects, to consider perceived workload and role ambiguity as job demands, perceived meaningfulness and job autonomy as job resources, and consider the influence of demands and resources on work engagement. Subsequently, the paper contributes to the literature in three different ways, which are explained in the following.

From the lens of the theory, the study has identified the effect of agile practices on job demands and resources. Compared to IS professionals who suffer from job demands such as large workloads and careerfamily conflict [6], our results indicate that agile 
practices affect team members' role ambiguity. With a higher amount of agile practices, team members' role ambiguity decreased. Interestingly, role ambiguity slightly increased work engagement. While perceived workload was identified as a key reason for exhaustion and turnover of IS professionals [6], agile practices show tendencies to decrease perceived workload in ASD projects and, in turn, increase team members' work engagement. Moreover, when agile practices were applied, team members' perceived meaningfulness and their job autonomy increased. With a consistent negative relationship of job resources and exhaustion [6], our research shows a positive relationship between job resources and work engagement in ASD projects. Consequently, agile practices support job resources such as perceived meaningfulness and job autonomy and, at the same time, diminish demanding aspects such as perceived workload and role ambiguity. However, we found that job resources significantly increase team members' work engagement, while the effect of job demands on work engagement remains minor.

Prior literature shows that ASD affects job satisfaction [56], stress and performance [29] and motivation [33]. Our study reveals different job demands and resources and indicates a significant relationship between job resources and work engagement. While job satisfaction is similar to satiation, work engagement connotes activation [31]. Above, job satisfaction is an evaluative description of characteristics and conditions of a job, whereas work engagement describes "individual experiences resulting from the work" [12]. As the agile manifesto values people over processes [19] and particularly points out self-organization [25], we expect work engagement to provide additional explanatory value in ASD.

Directly measurement of the level of use of agile practices has been defined as a key criterion for conducting research on agile [55]. Contrary to previous studies [e.g. 45], we directly assessed the extent of the use of agile practices. This allows us to measure and control for both direct and indirect effects of the dependent variable.

\subsection{Practical implications}

The job demands and resources of ASD identified in this study aim to provide leading managers with insights to explain the topic within their domain, enabling them to adequately transform the theoretical results into daily workflows.

The results of our study show that the usage of agile practices is a suitable instrument to have positively impact on working conditions of employees and at the same time to increase their meaningfulness.

In addition, our model shows that work engagement in agile teams can be influenced primarily by job resources, and not by reducing job demand. Accordingly, in the future, managers should focus on strengthening resources rather than trying to reduce demand.

However, if there is a need to reduce demands, we recommend taking additional measures in addition to applying agile principles, as the results show that agility primarily creates balance by strengthening resources instead of decreasing demands.

\subsection{Limitations and future work}

Whereas the results of our study provide essential contributions to both research and practice, we acknowledge certain limitations that should be kept in mind when interpreting the results and implications of our research. The present study focused on team members of ASD projects. We did not validate the effect of agile practices on particular roles within an ASD team, such as product owner or scrum master. The perception of particular job demands and resources, for example job autonomy, might vary between different roles. In line with [55], characteristics of the team environment might be crucial in determining whether agile practices can be used to their full potential. Thus, the effect of agile practices on job demands and resources of particular roles should be considered in future research. In addition, we focused in our study on team members of ASD projects in the automotive industry and our sample consisted of employees. Subsequently, the results of our study might not be representative for other branches, such as banking or finance and for selfemployed agile software developers. Future studies might take this into account and choose a more heterogeneous sample, comparing the effects in different branches.

\subsection{Conclusion}

In this paper, we propose and test a theoretical model to illustrate that agile practices both affect job demands and job resources in ASD teams. By focusing on the JD-R theory, the empirical analysis of our model reveals that agile practices decrease job demands (perceived workload and role ambiguity) and foster job resources (perceived meaningfulness and job autonomy) of team members. Job resources have been found to be positively related to work engagement in ASD teams. 


\section{References}

[1] S.T. Acuña, M. Gómez, and N. Juristo, "Towards understanding the relationship between team climate and software quality - a quasi-experimental study", Empirical Software Engineering, 2008, pp. 401-434.

[2] S. Addas and A. Pinsonneault, "E-Mail Interruptions and Individual Performance: Is There a Silver Lining?", MIS Quarterly, 2018, pp. 381-405.

[3] M. Ahuja and J. Thatcher, "Moving Beyond Intentions and Toward the Theory of Trying: Effects of Work Environment and Gender on Post-Adoption Information Technology Use", MIS Quarterly, 2005, pp.

[4] M.K. Ahuja, et al., "IT Road Warriors: Balancing Work-Family Conflict, Job Autonomy, and Work Overload to Mitigate Turnover Intentions", MIS Quarterly, 2007, pp. 1-17.

[5] M.C. Annosi, Magnusson, M., Martini, A., and F.P. Appio, "Social conduct, learning and innovation: an abductive study of the dark side of agile software development", Creativity and Innovation Management, 2016, pp. 515-535.

[6] D.J. Armstrong, N.G. Brooks, and C.K. Riemenschneider, "Exhaustion from Information System Career Experience: Implications for Turn-Away Intention", MIS Quarterly, 2015, pp. 713-728.

[7] A.B. Bakker, "Strategic and proactive approaches to work engagement", Organizational Dynamics, 2017, pp. $67-75$.

[8] A.B. Bakker and E. Demerouti, Job Demands-Resources Theory, in Job Demands-Resources Theory, C.L. Cooper and P.Y. Chen, Editors, Wiley-Blackwell, 2014.

[9] A.B. Bakker, E. Demerouti, and A.I. Sanz-Vergel, "Burnout and Work Engagement: The JD-R Approach", Annual Review of Organizational Psychology and Organizational Behavior, 2014, pp. 389-411.

[10] J.-M. Becker, K. Klein, and M. Wetzels, "Hierarchical latent variable models in PLS-SEM: Guidelines for using reflective-formative type models", Long Range Planning, 2012, pp. 359-394.

[11] W.W. Chin, B.L. Marcolin, and P.R. Newsted, "A partial least squares latent variable modeling approach for measuring interaction effects: Results from a Monte Carlo simulation study and an electronic-mail emotion/adoption study", Information systems research, 2003, pp. 189-217.

[12] M.S. Christian, A.S. Garza, and J.E. Slaughter, "Work engagement: A Quantiative Review and Test of its Relations with task and contextual performance ", Personnel Psychology, 2011, pp. 89-136.

[13] G.A. Churchill Jr, "A paradigm for developing better measures of marketing constructs", Journal of marketing research, 1979, pp. 64-73.

[14] K. Conboy, "Agility from first principles: Reconstructing the concept of agility in information systems development", Information Systems Research, 2009, pp. 320-354.
[15] M. Cotes, Predictors of Employee Engagement and their Contribution to Organizational Success. 2014, Honors Thesis.

[16] J.D. Couger, R.A. Zawacki, and E.B. Oppermann, "Motivation Levels of MIS Managers versus Those of Their Employees", MIS Quarterly, 1979, pp. 47.

[17] R.L. Daft and R.A. Noe, Organizational Behavior, Harcourt College Publishers, 2001.

[18] Dimensional Research, Testing Trends in 2017: A survey of Software Professionals 2017.

[19] M. Fowler and J. Highsmith, "The agile manifesto", Software Development, 2001, pp. 28-32.

[20] D. Gefen and D. Straub, "A Practical Guide to Factorial Validity Using PLS-Graph: Tutorial and Annotated Example", Communications of the Association for Information Systems, 2005, pp. 91-109.

[21] A.H. Ghapanchi and A. Aurum, "Antecedents to IT personnel's intentions to leave: A systematic literature review", Journal of Systems \& Software, 2011, pp. 238-249.

[22] J.R. Hackman and G.R. Oldham, "Development of the job diagnostic survey", Journal of Applied Psychology, 1975, pp. 159.

[23] J.F. Hair, et al., Partial Least Squares Strukturgleichungsmodellierung (PLS-SEM), Verlag Franz Vahlen GmbH, München, 2017.

[24] J. Henseler, C.M. Ringle, and M. Sarstedt, "A new criterion for assessing discriminant validity in variance-based structural equation modeling", Journal of the Academy of Marketing Science, 2015, pp. 115-135.

[25] R. Hoda and L.K. Murugesan, "Multi-level agile project management challenges: A self-organizing team perspective", Journal of Systems \& Software, 2016, pp. 245-257.

[26] D. Joseph, et al., "Turnover of information technology professionals: A narrative review, meta-analytic structural equation modeling, and model development", MIS Quarterly, 2007, pp. 547-577.

[27] N. Kawai and A. Mohr, "The Contingent Effects of Role Ambiguity and Role Novelty on Expatriates' Workrelated Outcomes", British Journal of Management, 2015, pp. 163-181.

[28] S.L. Kirmeyer and T.W. Dougherty, "Work load, tension, and coping: Moderating effects of supervisor support", Personnel psychology, 1988, pp. 125-139.

[29] M. Laanti. "Agile and Wellbeing--Stress, Empowerment, and Performance in Scrum and Kanban Teams", in 46th Hawaii International Conference on System Sciences (HICSS). 2013: Hawaii.

[30] G. Lee and W. Xia, "Toward agile: an integrated analysis of quantitative and qualitative field data on software development agility", Mis Quarterly, 2010, pp. 87-114.

[31] W.H. Macey and B. Schneider, "The meaning of employee engagement", Industrial and organizational Psychology, 2008, pp. 3-30.

[32] K. Mathieson, E. Peacock, and W.W. Chin, "Extending the technology acceptance model: The influence of 
perceived user resources", ACM SIGMIS Database: the DATABASE for Advances in Information Systems, 2001, pp. 86-112.

[33] O. McHugh, K. Conboy, and M. Lang, "Using agile practices to influence motivation within IT project teams", Scandinavian Journal of Information Systems, 2011, pp. 59-84.

[34] S.C. Misra, V. Kumar, and U. Kumar, "Identifying some important success factors in adopting agile software development practices", Journal of Systems and Software, 2009, pp. 1869-1890.

[35] C. Pflügler, M. Wiesche, and H. Krcmar. "The dualsided effect of project failure on IT professionals", in Proceedings of the 2016 ACM SIGMIS Conference on Computers and People Research. 2016: Alexandria.

[36] C. Pflügler, M. Wiesche, and H. Krcmar. "Subgroups in Agile and Traditional IT Project Teams", in Hawaii International Conference on System Sciences (HICSS). 2018: Big Island.

[37] G.L. Polites, N. Roberts, and J. Thatcher, "Conceptualizing models using multidimensional constructs: A review and guidelines for their use", European Journal of Information Systems, 2012, pp. 22-48.

[38] L. Przybilla, M. Wiesche, and H. Krcmar. "The Influence of Agile Practices on Performance in Software Engineering Teams: A Subgroup Perspective", in Proceedings of the 2018 ACM SIGMIS Conference on Computers and People Research. 2018:

[39] E. Ramirez, M.E. David, and M.J. Brusco, "Marketing's SEM based nomological network: Constructs and research streams in 1987-1997 and in 1998-2008", Journal of Business Research, 2013, pp. 12551260.

[40] C.M. Ringle, S. Wende, and J.-M. Becker. SmartPLS 3. 2015, Available from: www.smartpls.com.

[41] J.R. Rizzo, R.J. House, and S.I. Lirtzman, "Role conflict and ambiguity in complex organizations", Administrative science quarterly, 1970, pp. 150163.

[42] P. Rodeghero, et al., Detecting User Story Information in Developer-Client Conversations to Generate Extractive Summaries, in Detecting User Story Information in Developer-Client Conversations to Generate Extractive Summaries, IEEE, 2017.

[43] B.D. Rosso, K.H. Dekas, and A. Wrzesniewski, "On the meaning of work: A theoretical integration and review", Research in organizational behavior, 2010, pp. 91-127.

[44] P.S. Rutner, B.C. Hardgrave, and D.H. McKnight, "Emotional Dissonance and the Information Technology Professional", MIS Quarterly, 2008, pp. 635-652.

[45] Salge CA de Lima and N. Berente. "Pair Programming vs. Solo Programming: What Do We Know After 15 Years of Research?", in 49th Hawaii International Conference on System Sciences. 2016:
[46] W.B. Schaufeli and A.B. Bakker, "Job demands, job resources, and their relationship with burnout and engagement: A multi-sample study", Journal of organizational Behavior, 2004, pp. 293-315.

[47] W.B. Schaufeli, A.B. Bakker, and M. Salanova, "The Measurement of Work Engagement With a Short Questionnaire", Educational and psychological measurement, 2016, pp. 701-716.

[48] C. Schmidt, et al., How Agile practices influence the performance of software development teams: The role of shared mental models and backup, in Thirty Fifth International Conference on Information Systems. 2014: Auckland.

[49] P. Serrador and J.K. Pinto, "Does Agile work? - A quantitative analysis of agile project success", International Journal of Project Management, 2015, pp. 1040-1051.

[50] M. Siponen and A. Vance, "Neutralization: New insights into the problem of employee information systems security policy violations", MIS Quarterly, 2010, pp. 487-502.

[51] Standish Group. The Chaos Report 2015. 2015 2015, Available from: https://www.standishgroup.com/.

[52] M. Stoica, et al., "Analyzing Agile Development-from Waterfall Style to Scrumban", Informatica Economica, 2016, pp. 5-14.

[53] M.V. Tatikonda and S.R. Rosenthal, "Successful execution of product development projects: Balancing firmness and flexibility in the innovation process", Journal of Operations Management, 2000, pp. 401-425.

[54] B. Tessem, "Individual empowerment of agile and nonagile software developers in small teams", Information and Software Technology, 2014, pp. 873-889.

[55] J. Tripp. "Thoughts on Current and Future Research on Agile and Lean: Ensuring Relevance and Rigor", in Hawaii International Conference on System Sciences. 2018: Hawaii.

[56] J.F. Tripp, C. Riemenschneider, and J.B. Thatcher, "Job Satisfaction in Agile Development Teams: Agile Development as Work Redesign", Journal of the Association for Information Systems, 2016, pp. 267-307.

[57] D. West, et al., Agile development: Mainstream adoption has changed agility, in Forrester Research. 2010.

[58] M. Wiesche and H. Krcmar. "The relationship of personality models and development tasks in software engineering", in Proceedings of the 52nd ACM conference on Computers and people research. 2014:

[59] L. Williams, A Survey of Agile Development Methodologies. 2007.

[60] Q. Zhou, et al., "Supervisor support, role ambiguity and productivity associated with presenteeism: A longitudinal study", Journal of Business Research, 2016, pp. 3380-3387. 